tos da a luz un enorme feto de 4.800 gramos de peso, muerto y con los primeros signos de maceración. Debido al tamaño del feto hubo alguna dificultad en el desprendimiento de los hombros.
Durante el puerperio subió la temperatura a 39,5 grados, el quinto $\mathbf{y}$ sexto dia a causa de una endometritis benigna. Al octavo día se inició una psicosis y hubo necesidad de pedir su traslado dara el Frenocomio.

\title{
Conducta en el desprendimiento prematuro de la placenta normalmente insertada
}

\author{
Por el doctor Jaime Corral Maldonado
}

Ex-Jefe de Clínica Obstétrica.

(Coninuación de la pág 48 del número arterior)

Historia número 1.429. Servicio Profesor V. Rodriguez Aponte. Año 1948. Edad: 38 años. Tercer embarazo. Edad del embarazo al entrar al servicio 7 meses. Cuenta la enferma que su embarazo evolucionó normalmente hasta el dia 28 de agosto, fecha ésta en que notó hemorragia de sangre roja, que le duró según dice ella 15 minatos y se le suspendió espontáneamente. Que el 2 de septiembre a las 18 horas, sintió dolor muy intenso en el flanco derecho y a las 23 , le sobrevino de nuevo la hemorragia de sangre roja. Examinada a las 18 horas del 3 de septiembre, hora en que llegó al Hospital, se aprecia: Pulso 100, Tensión amterial Mx. $111 / 2$ y Mm. 6. Alt uterina 26 centimetros, matriz en gero estudo de hipertonia feto en resentación de vertice $O$. I. D., auscultación feial positiva, Tacto vaginal: Gran cantidad de coágulos en la vagina, cuello con 7 centimetros de dilatación, bolsa intacta, cabeza por encima del estrecho superior en $O$. D. T., no se palja placenta, hemorragia vaginal discreta. Se hace el diagnóstico de despren imiento prematuro de la placenta normalmente insertada $\mathbf{y}$ se decide terminar el parto mediante una version por maniobras internas, la que se logra practicar facilmente debido a que la matriz relaja muy bien a la anestesia profinda con éter, a que el cuello se logró llevar a la dilatación completa, y a que el feto era de pequeño tamaño. Niño vivo que pesa 1600 gramos y respira espontaneamente, pero que muere a la $1 / 2$ hora. Expulsada la placenta se comprueba el diagnóstico de desprendimiento prematuro. Puerperio normul. La preciente sale a los 12 dias del hospital por curación. 
Historia número 1.707. Servicio Profesor V. Rodriguez Aponte. Año 1948. Edad 21 años. Segundo embarazo. Edad del embarazo al entrar al servicio: $71 / 2$ meses. Dice-la paciente que su embarazo había evolucionado normalmente hasta las 23 horas del día 14 de octubre, hora en que espontáneamente se iniciaron los dolores del parto. Examinada a las 9 a. m., de ese mismo día se encuentra: Pulso 80 , tensión arterial $13 \times$ $71 / 2$, altura uterina 28 centimetros, matriz de consistencia normal, contracciones uterinas cada 5 minutos, feto en presentación de pelvis completa S. I. I., auscultación fetal negativa. Tacto vaginal: Hemorragia vaginal discreta, cuello completanente borrado, blando, con 7 centimetros de dilatación, bolsa intacta, presentación de pelvis completa S. I. A., en el estrecho medio, no se palpa placenta. A las 9 y 15 se rompen artificialmente las membranas y sale abundante líquido amniótico teñido de sangre. Se hace el diagnostico de desprendimiento prematuro de la placenta y se decide entorces terminar el parto practicando una extracción podálica. Para tal efecto se anes- tesia la paciente con Eter, se termina manualmente la dilatación del cuello y se extrae con facilidad un niño muerto que pesa 1.800 gramos. Expulsada la placenta se comprueba su desprendimiento. Puerperio normal. La paciente sale del Hospital a los 10 dias por curación.

\section{Bihliografía.}

Carl Henry Davis. Gynecology and Obstetrics. 1942.

Williams. Obstetricia. 1938.

Titus Management of Obstetrics Difficulties. 1940.

A. Doderlein. Tratado de Obstetricia. 1938.

Manuel L. Pérez. Tratado de Obs. tetricia. 1943.

Bland and Montgomery. Practical Obstetrics. 1940.

De Lee- Greenhill. Principles and Practice of Obstetrics. 1947.

Adair. Obstetrics and Gynecology* 1940.

L1. Sexton-A. T. Hertig- Premature Separation of the Nomally implanted Placenta. Am. Jr. of Obst. and Gyn. vol. 59 No 1. 1950.

Hogamos a todos los Obstetras y Ginedlogos del pais, que nos envien su drección con el fin de hacerles llegar la revista 